\title{
Philosophical Paradigms Errors Entangled the Development of Student Research and Scientific Arts Education
}

\author{
Dr. A.M.Susilo Pradoko, M.Si. ${ }^{1}$

 \\ *Corresponding author.Email: Susilo_Pradoko@uny.ac.id
}

\begin{abstract}
The scientific paradigm developed from the era of mythic society around before the 15 th century and then stepped on modern society in the early 17 th century. In this modern era the rapid development of science with the paradigm of logical empiricism, realistic observation through the senses and the laboratory and precise calculations. In this era the industrial world, technology and technology are growing rapidly. In the social world sociology emerged with the character Auguste Comte. The world of education also follows the tradition of modern thought with the positivistic thought of Comte. The era of philosophical thought has developed again, weaknesses in the modern era are criticized with the emergence of postmodern philosophical thoughts. In this paper describes the misuse of the paradigm so that the positivistic paradigm is applied to the world of cultural meaning. Formatting guidelines for writing research thesis, inappropriate thesis or dissertation presented in this paper are: (a) identification of objects to be studied, (b) research questions in chapter II (c) priority judgment (d) data description format and discussion in chapter four. Glossary of terms: research subjects, research instruments, expert validity and the emergence of the term respondent in qualitative research.
\end{abstract}

Keywords: Philosophical, Modern, Positivistic, Emic, Postmodern Paradigm

\section{INTRODUCTION}

In the era before the 15th century, it was an era of mythical thinking, people explained social phenomena with stories about gods and goddesses, stories of magical powers possessed by nature. In the 17 th century came the industrial era, the emergence of this industrial era influenced the rationale of modern philosophy. This philosophy emphasizes that what is a myth, not based on facts is not scientific, this thought is then referred to as the empirical school of thought, Benton and Ian Graib stated in short words: "Seing is believing, I see it with my own eyes" [1]. Modern thought develops empirically rational thinking, empirically rational physical and mathematical sciences that can be calculated and appear real. This knowledge has an impact on extraordinary industrial progress, an industrial revolution emerged at that time. Industrial engines are rationally empirically mathematical. In the social world, the emergence of the French philosophy figure, Agust Comte, who criticized the theology of science, this science as a metaphysical explanation is an abstract explanation of this science as pseudo scientific. Such knowledge needs to be changed to the level of scientific knowledge, scientific science based on observation and experiment. Scientific theology as negative task science is being replaced by revolutionary science with positive knowledge to build social harmony [1]. Since then, positivistic research has emerged in the world of social science, its science is referred to as social physics or sociology. In the world of basic education, the philosophy of empirical rational thought also continued to develop, which led to various teacher-student interaction studies based on this philosophical basis. The combination of natural science rationale based on empirical thinking, rational is realized in the right calculations combined with positivism thinking is applied in educational studies and concepts of education policy based on the application of empirical-mathematical positivistic research.

In subsequent developments this empirical-mathematical positivistic scholarship was challenged by philosophers as well. One of them is Ludwig Dilthey, he stated that human social science is different from natural science. Natural Science is referred to as Naturwissenschaften while scientific human-community relations are referred to as Geisteswissenschaften. (Hardiman, 2015: 66). The critical power to respond to weaknesses also continues with the emergence of Postmodern figures, who provide many other discourses for social research, other ways for social research. The method of social research is not by calculating empirical quantitative numbers but seeking the quality of a society's content, then becoming qualitative studies. Quantitative research is no longer able to reveal values and meanings for a society because the meaning and value in society does not appear empirically but is normalized in the system of public cognition. 
Indeed, the positivistic era has developed into the postpositivistic era, but the world of educational research is still complacent in focusing on the era of positivistic glory. Scientific access to the post-positivism paradigm is often closed because of a lack of understanding of critical thoughts that want to improve the weaknesses of the scientific era. Era Positivistik strong rooted in the paradigm of thinking this hampers the world of student research and the world of art education research. Problems arise from the term to the operational level in the research of students and researchers in education. In this paper, we will describe the weaknesses of positiveistic thinking and the misconceptions of postivistic thinking that are applied in research for the purpose of strengthening beyond the meanings and values and social interaction of the community.

\section{DISCUSSION}

In the modern era the theory emerged that the most correct science was knowledge based on laboratory work, namely empirical experience, or the flow of empiricism. Trust and based roughly are not scientific. The source of human knowledge about the world is proof of our sense of taste. The empirical states that true knowledge is knowledge that can be seen by themselves through empirical observation [1]. This approach that seeks objectivity and freedom of value has been greatly influenced by natural science methods that have been successfully applied in modern industry. Auguste Comte states that theology is the level of metaphysical science in which the evidence is explained in terms of abstractness. This kind of scientific process is abstract scholarship so that it produces erratic results, negative results. This kind of scholarship is a pseudoscience in theology and belief systems and even myths. Comte emerges positive knowledge based on empirical observations through observing laboratory models, all of which are tangible evidence that can be seen directly, observed, touched and able to be calculated in real terms as positive knowledge to construct social harmony. His knowledge is referred to as social physics or referred to as sociology. Scientific knowledge that cannot be proven empirically is considered not knowledge, the characteristics referred to as knowledge are: (1). Empirical calculations in natural science are accepted. (2.) Sain is considered as the highest level of knowledge if it is through the modern empirical paradigm. (3.) The Scientific Method with empirical studies is applied in human social life as a solid social science. (4.) Social scientific knowledge can be applied to control or regulate individuals or social groups. Social problems and conflicts can be identified and solved one by one on the basis of expert knowledge of social scientists, as well as the experts of natural sciences involved in solving the problems of technological engineering. This social saitifik project program is referred to as social engineering, social engineering (Benton and Ian Craib, 2002: 23).

The era of posistivism paradigm with which differentiating concepts are said to be scientific and that are not in this mindset is firmly rooted in the modern era, so also in the thinking of our education world. Derivative concepts that provide rules: empirical, experimental, visible through the senses, can be quantified, approaches that seek objectivity and freedom of value, form the rules of general rules (unified scientific), based on laboratory observation work and the power of authority Science scholars through EST experts in science and social fields for strong technological and social engineering are rooted in the world of education, especially in Indonesia. While the critical power to give input to improve the modern paradigm is very little attention. The philosophical basis after the modern era was not developed into a science that was able to further refine modern thought. While in the West itself, the place of origin of the development of science has been considered as inadequate in the 19th century positivism in the social sciences to understand humans and society. Even people criticize positivism as the root of modern totalitarian dehumanization and domination [2].

Complex social problems with network links, contextual cannot be imposed with a positivistic paradigm model, for that paradigm outside positivistic is very important to get attention so as not to form educational researchers and students to think unified scientifically and think of a paradigm of objectifying humans, but thinking -the thought of subjectiveizing really needs to be developed in the postmodern era society and this hyper realist society. Limited place in writing this script, then only presented the problem of the implementation error of the positivism paradigm that is applied to student research rules and beginner education researchers result in students and the education world falling into the rules, while the rules themselves are not appropriate for world research socialsociety and the art world. While in this paper will reveal positivistic contaminated terms for socio-community research. Philosophical paradigm in order to expose beyond meaning in society is forced to positivistic paradigm so that there is an inaccuracy in the target, the inaccuracy of the term makes targets targeted blurred and educational and artistic research science becomes trapped in a pool of blunders. The terms highlighted in this paper are the rules for writing scientific papers that are the reference for writing theses, theses, or dissertations. Writing wrong terms in socio-community research, art, culture and art education. The terms of the preparation guide for the thesis, thesis and dissertation are: Rules must be an identification format in student proposals and research reports. Rules must appear in the data description format in the research report. The rules must have a discussion format in the research report. The term error caused by exposure to the positivistic paradigm: research subjects, instruments, expert validity. These terms are then reviewed in the background of the previous thought patterns and then expressed the terms and paradigm of the right paradigm for qualitative research which is actually very more complex with various methods rather than positivistic according to the social context of the community. 


\subsection{Format of Snare Positivistic Guidelines for Research Thinking Patterns}

Positivism thinking patterns always emphasize the first thing to do is observe, after observing make (a) identification of the object of the observed object. After a literature review there are still rules for making (b) research questions, this is a waste of paper because qualitative research has been made before entering the literature review chapter. Another mistake is the pattern of thinking by asking experts, experts, if it has been asked by (c) economic judgment, the research process is considered complete and valid. The next mistake in thinking patterns is the rule of (d) the data description format and discussion in chapter four, this makes qualitative research a misdirected one, one of the pathways to become a quantitative research flow pattern which describes statistical data first, enters into the formula referred to and then there is a round of discussion on the results of the calculation in the formula. Qualitative research differs from the flow of thinking, if forced to do it is wrong and experiences waste of writing.

\subsubsection{Rules of the Guide Include Problem Identification in Qualitative Research}

The basis of the qualitative research paradigm is intersubject, the social community studied is also a subject, because qualitative research attempts to reveal the experiences of the people under study. The culture owner community is not considered an object like positivistic research determines the respondent, the respondent in positivistic is the object because the respondent does not have any power over the research treatment. Researchers have complete control over the treatment of humans who are respondents. Research on objects like goods, observed first, then identified all things related to the goods, then the formulations of the existing problems are made. After a variety of new problems were discovered, one or two problem problems were then selected which were then used as material for the research object.

Qualitative research is not the case, qualitative research attempts to reveal the culture of the local community under study. Qualitative researchers by looking at and interested in the culture of the local community, do not need to make identification in advance. Qualitative researchers usually have been directly interested in a cultural aspect of society, so there is no need to register and register any community problems that will not be examined in the end. A qualitative researcher from Russia, for example, wants to examine the meaning of Gunungan Lanang and Gunungan Wadon in the Garebeg Ceremony in the Yogyakarta Palace, he does not need to have to identify all the problems related to the garebeg ceremony. He does not need to add other aspects of the problem, for example: Are there conditions to bring gunungan lanang, wadon; What is the cooking process for making the Mount? What costume is used for the carrier of the Gunungan, how much economic costs are incurred in the framework of the Garebeg Ceremony and the Gunungan, and so on can dozens of issues be identified in the Garebeg Ceremony with the Gunungan. This is the redundancy of the rules, there must be identification in the format of qualitative research. A Russian researcher only wanted to examine the meaning of the gunungan offerings. This is then the focus of the research. The focus of the research then developed into the formulation of the problem to be expressed for example: why are the foods arranged by certain foods, what does each food mean for the community, what do these foods mean to the community? Does the food become a symbol, icon and index for the people to behave? Qualitative researchers when they want to research the meaning of Gungan Lanang and Wadon, do not need to be preceded by the necessity of identifying problems. The identification format of this problem is placed after the introduction. This requirement is redundant because researchers have material that will be studied, already know the direction and purpose to be investigated why it must be bothered with additions to the identification which are not examined at the end. At the time of the introduction, however, it was better to purge that what was examined in the aspects of the meaning of Gungan Lanang and Wadon in the context of the Garebeg Sekaten Keraton Yogyakarta Ceremony, for example. One time a qualitative researcher walked along ecological tourism, seeing that there were rice plants that were different from the others, the rice plants were higher than other rice plants around the rice fields. He decided to examine the type of rice and how long it would take for the rice harvest. When he has decided on this focus, he does not need to first go into the fields to observe all the problems in the rice field area that is higher. He did not write down the problem that there was a problem of weeds growing there, there was a problem of the irrigation system for the rice, there were problems with the pest-pests around the rice fields and so on which could be dozens or even dozens of problems that could be written down, this is what makes waste of work write the study. This error is due to the pattern of positivistic thinking, differentiating goods or something being studied, applied to qualitative philosophical thinking patterns that emphasize inter subjective. The format of identifying problems in qualitative research should be eliminated, because it makes confusion of thinking patterns and wasteful problems which ultimately are not the purpose to be studied.

\subsubsection{Format After Chapter II There are Research Question Points}

Research questions in the case of qualitative research have been stated in the Chapter of Preface. After describing events in the community or observations of material culture, qualitative researchers see irregularities, peculiarities, uniqueness and admiration in these social 
phenomena. These kinds of things are then the qualitative researchers want to express more deeply, what is behind this social phenomenon. Qualitative researchers after learning a lot (read: reading) from the case that will be examined in the community then determine the focus that they will study. After being caught in the focus of the research, then proceed with the formulation of the problem to be examined based on the research focus that has been selected. The problem formulation has been explained after the focus of the research by making research questions that are in accordance with the focus, so there is no need to re-write the research questions in the final chapter of Chapter II. Qualitative researchers when they are interested in finding interest in the case of the phenomena of the present and past society have read a lot and sometimes the initial studies so that the focus and research questions are clear. Literature study in Chapter II is more looking for solutions to problems based on the focus. What kind of conditions will the community examine? What kind of analysis is right for the case he is researching. Research journals that have reviewed and researched the intended community or culture. When finding new things when reading various books, fibers, inscriptions and pre-elemanary research, the researcher automatically sharpens his research questions in Chapter I. When the proposal has been made, the flow of thought has been done since the Introduction to Chapter I with the focus of the problem and the corresponding research questions so that it is no longer necessary in Chapter II to present the research questions again. Further detailed and in-depth questions to reveal beyond that are not easy to see in the community are not in Chapter II where they are, but in Chapter III in the interview section and then more research questions are developed in the attachment section. Rewrite the research questions in Chapter II is unnecessary waste, is the tutology of Chapter I. This thinking is exposed to positivistic thinking after observing natural events with various sources of reading and then determining the hypothesis. Determination of this hypothesis is indeed coherent with what will be revealed because before conducting a research laboratory has found predictions of problem solving through readings and other sources so that finally can firmly conclude the null hypothesis (H.O) and alternative hypothesis (H.A.). The formulation of the $\mathrm{HO}$ and $\mathrm{HA}$ sentences became more convincing after reading the various references in Chapter II. Qualitative research has no hypothesis, because if hypothesized it could be that many studies have failed hypotheses. Qualitative research does not need a hypothesis, it is not appropriate to put back the research question in Chapter II as an analog substitute for a hypothesis like a positivistic perspective.

\subsubsection{Rules Require Validity of Expert Judgment}

Qualitative research aims to reveal the meaning, values, symbols, knowledge systems in a society. In order to reveal the meaning, value, system of knowledge and symbol of a society, we learn from the people we study. Our society is carefully subjected to this, this is the side of the philosophical nature of qualitative research, society is not regarded as empty paper but the community has a lot of things about the internalization of culture. Society is not empty paper that must follow the rules of the researcher or in logical positivism, the people studied as objects. Criticism of logical positivism is the way of reducing human beings, their knowledge and interests only as empirical objects without free will [5]. In qualitative expression of meaning in society, society is considered a subject, then the position between the researcher and the one studied is inter-subject. The researcher learns a lot from the people studied, because the researchers who learn from the people they study are truths from the point of view of the people they study. The truth from the emic side, namely calculation, description, and analysis expressed in the context of the terminology of conceptual schemes and categories that are very meaningful and in accordance with the members of indigenous communities whose behavior and cultural beliefs are being studied [3],[7].

The criteria of truth are not from the community of social sciences experts, like in the natural sciences and engineering, the determination of truth is obtained from technical experts as well as experts in exact and natural sciences. Determining the truth in the area of the people who own the culture, because indeed those who carry out their own cultural symbols and they are the owners of the culture, the perspective of truth is from them, because we as researchers actually learn from them. In such a philosophical paradigm, it is not true that a world expert in natural and social sciences is used as a benchmark to validate the validity of research results. Doctoral academics and the highest positions of professors are not entitled to declare their own version of the true meaning, validate the research of the community, but what is entitled is the meaning of the people who own the culture. New doctors and professors have the right to validate research if he himself has repeatedly researched the same culture of society, if he has never researched the same society at all, he has no right to judge that the idea of his meaning is the most correct. The rules must be judgmental to validate research on the meaning of community culture in qualitative research. Social scientists, doctors and professors will, after all, be involved in the rules format there as resource persons to sharpen research methods when conducting ethnography. 


\subsubsection{Format of Chapter IV with Terminology of Data Descriptions and Discussion}

Data search and data processing as well as analysis on qualitative research were carried out during the research process period when plunging into the field. Somewhat different from the quantitative research process that collects the questionnaire data first (for example) only after the questionnaire has been processed, so the recommendation of the quantitative paradigm model process so that the data collected first is analyzed makes it difficult for researchers to work. The mindset and its implications for best practice in different fields so the rules should also be different. To make it clearer, the field work process and draw conclusions in the circular process are presented here:

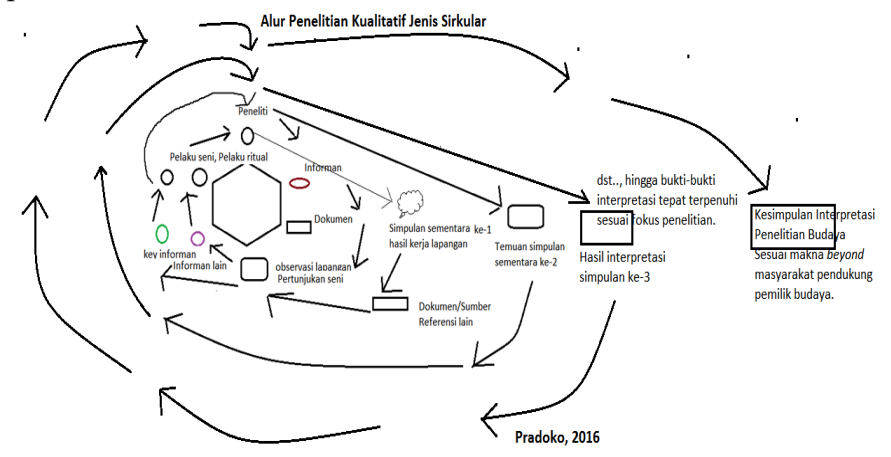

Figure 1 Flowchart of Circular Model Qualitative Research Flow [7]

Throughout the duration of the study the ethnographer is tasked with finding answers to the meaning of the culture under study every time the data is found meaning meaning is always evaluated by comparing all categories of sources and information in the field. Through this circular process, the answer from the problem formulation reveals the cultural meaning that is being investigated more precisely and reliably with the evidence in the cultural context of the local community.

The guide's qualitative guidelines require the format to be (A). a description of the data, in fact it is not in place, because it is an imperative that promotes work. As explained in qualitative research, the data exposure process is also processed and analyzed and the conclusions drawn. In vain work for students if they have to collect chronological data throughout the research time process and after that it is analyzed. The research process of interwoven fieldwork between data, verification, analysis and conclusions and even falsification is done during doing field work. The abolition of these different chapters can we examine the case of historical research such as "Arrest of Prince Diponegoro to Death in Makassar". For example, the exposure can be given in the following format: (a). Deception Dutch Deception: the description contains manuscript evidence and the other when the Dutch invited to negotiate Prince Diponegoro. (b). Entering the First Prison: His description of Diponegoro entered the detention cell and the manuscript evidence and others when he was in prison. c. Son Visit of the Governor General of the Netherlands: written evidence when the Dutch Governor's son visited Dipnegoro. Evidence of dialogue between Dipnegoro and Putra Governor etc. d. Prince Diponegoro Died His description of the process of the death of Pangeran Dipnonegoro, proof of manuscripts and chapters or anything else such as sketches of drawings and so on when Diponegoro died, of course there were also journal evidence.

This example is just a description of how futile and not coherent if all data must be put in the data description section. Data since the deception until the death of Prince Diponegoro in Makassar is explained first in the data description section. The data displayed throughout the process can reach tens to hundreds of pages. The data is like a warehouse with tools, tangible but scattered without meaning and very meaningless to anyone who reads it. Likewise for the example of field work it will be a futile job if forced to use a linear quantitative logic, the data is collected first and then processed in the discussion. Dissolution in research Changes to the meaning of the Shiva Prambanan temple from the 9th century to the 20th century: The Archaeological Study of Pengethuan is not by describing all the data first and then being discussed. Dissolution in the following order: Chapter 1. Introduction., Chapter 2. Shiva Prambanan Bathing as Efforts to Seek Meanings, Chapter 3. Semiotic Analysis of Roland Barthes and Discourse of Foucauldian Genealogy on Temple Functions, and Meanings of Statues and Reliefs., Chapter 4. Temple Functions, Meanings of Arca and Prambanan Ramayana Relief in Islam and Colonial., Chapter 5., Function of the Temple, Meaning of the Independence Day Ramayana Statue and Relief., Chapter 6. Archeology of Thought Change of Temple Function, Meaning of Statues and Ramayana Prambanan Relief., Chapter 7. Conclusions and Implications of Research Results [6].

Research on the Search for the Meaning of Ramayana Relief Effect of Hindu, Islamic, Colonial and Independence Power, research conducted by Susilo Pradok in 2015. The format displays the complete data in advance of the era of Hindu power, in the form of inscriptions, fiber, journals, books, teachings of the scriptures Hinduism is explained by all the data obtained in the period of power of Islam, then the data at the time of the influence of the power of Islam after that all the data on the influence of the power of the era of independence. Readers who are treated with this kind of data from the time of the influence of Hindu power to the influence of the independence power are very irrational and information dissipated. All of 
these data if presented in more than sixty sheets, then what the meaning of the data shows is, even though the data has been selected according to the focus of the research study. A format that fools students or models of all qualitative research must go through the process of exposing the data first. In this case the description data of research results are presented starting from the Hindu, Islamic, Colonial, Independence era. After being explained, all of them were only discussed one by one and their rationality and analysis logic were broken down. The abolition becomes more interesting and coherent when the meaning of the Ramayana relief in the power of Hinduism data, evidence, manuscripts, artifacts, chapters, journals, inscriptions are all processed, analyzed, verified, falsified by the exposure of the Influence of Hindu Power to conclusions on the influence of the Hindu power. Furthermore, it was explained in the Islamic period. Colonial, and Independence.

\subsection{Mistakes Terms with Posistivistic Terminology.}

Glossary of terms that will be described in this paper are only three terms: research subjects, instruments and expert validity.

\subsubsection{Research Subject}

In quantitative research often uses research subjects that are people who are asked as a source of research data. Research data sources are usually only part of the sample. Data sources from people as samples are often referred to as respondents. In qualitative research do not use the term research subjects or also called respondents because the research process does not go through the stages of the process of determining the population and sample. The appropriate terms used in qualitative research are informants and key informants. The collection of how many informants and key informants is not based on the thought of the sample to be the respondent, but based on the focus of the search for the cultural meaning of the local community. In qualitative research, the informants can only be 2 people, even only 1 person, but it is appropriate and reliable, for example, only want to know the names of kinship terms in the tribe. How many informants are asked for information depends on how accurate and reliable the informant answers to the cultural problems that are being sought.

\subsubsection{Research Instruments}

In quantitative research to obtain answers to research questions that are sought by using questionnaires or items of written evaluation, questionnaires or evaluation items are then referred to as instruments. Instrument to collect answers to what is being sought. This is the implication of the thought of the respondent as an object, whatever is treated by the respondent is up to the researcher, using the ethical paradigm. The tool for obtaining answers from the respondents is referred to as an instrument.

Qualitative thinking patterns differ from the angle of their philosophical thinking, if positivistic thinking considers the person being examined as an object, as a white paper, the treatment of it is up to the researcher. Qualitative researchers are paradigmatic between subjects, researchers as separate subjects and on the other hand the person being studied is also a subject, so researchers often call others, others have their own authority in accordance with their cultural categories. Qualitative researchers do not need instruments or make evaluation points for those studied. Qualitative researchers are learning from them about their own culture. Thinking about instruments in qualitative research is the researcher itself [4] is also an incorrect explanation idea. Because humans are not tools, humans cannot be equated with questionnaire files or evaluation items or operational standard observation items like in a laboratory. This idea means disguising people with things, this is still affected by positivistic logic. Instruments in qualitative research are of course the tools used to reveal the cultural meaning in the community under study. These tools are tape recorders, video / audio recorders, camcorders, cameras, daily notebooks and laptops, cellphones, as well as a question reference grid in accordance with the research focus as well as research questions to further deepen the problems being researched.

\subsubsection{Expert Validity}

Qualitative research often aims to express the meaning of culture, the symbol system, the social institutions of the people under study. The meaning of culture, symbol system, and social institutions belong to the local culture, of course the people who know and experience it are the people themselves. People outside the community culture that he studied must not be able to reveal and feel as much detail as the local community. A scientist who has never examined the culture of society $\mathrm{x}$ for example, has no right to give judgment, conclusions on his own views, even though he has a high academic position and professional position. The validity of the expert is not the college community scientist, but the validity of the meaning, the symbol system, the social institution system is more in the society who owns the culture itself. The right term for this case is more appropriate by using informants and key informants. The informants were people who gave various information about local culture while key informants is $\mathrm{s}$ a key figure who best understands and deepens the culture of 
the local community. This is the emic validity that is emphasized rather than misdirected to be ethical validity, based on the scientific community outside the local culture.

\section{CONCLUSION}

The era of society before the 15 th century to the beginning of the 17th century was an era of mythical society. This era of mythical society was criticized until the era of modern society that was characterized by rational and empirical emerged. In this era of modern scientific thinking that supersedes mythical thinking this has a tremendous impact on the fields of engineering, industry and economics. In this era positivistic thinking emerged in the field of social sciences through the thinking of the figure Auguste Comte. Comte states that as social physics or sociology, the characteristics of social science are: (1). Empirical calculations in natural science are accepted. (2.) Sain is considered as the highest level of knowledge if it is through the modern empirical paradigm. (3.) The Scientific Method with empirical studies is applied in human social life as a solid social science. (4.) Social scientific knowledge can be applied to control or regulate individuals or social groups. This science is ambitious to be a science used throughout the world of human social science, in order to construct humans, this understanding is called a unified scientific. The modern packaging era and this successful positivistic paradigm are also applied in the world of education.

The modern era has on the one hand has advantages but on the other hand there are also many weaknesses in the aspect of humanizing human life. Modern thought was then criticized by post-modern philosophers. The end of the 20th century was the emergence of the ideas of the critical world of postmodern philosophers. The Modern Era continues and the Postmodern Era appears and accompanies it. Duni education is also a loyal adherent of the era of modern thought since its first appearance, but until now the world of education is still lulled by the modern era of positivistic. The era has changed but thought is still in the context of modern education, unified scientific and positivistic. The thought of positivism has an impact on the rules of research on the type of philosophy between subjects and objek to be used as research between subjects researchers to subjek. This paradigm is powerful, so that equating logical positivist rules becomes a qualitative rule of culture. Educational researchers, students are trapped in the positivistic paradigm which is strongly influenced by instrumental rules. Problems arise in the format of guidelines for writing rules and errors of mindset so that the use of positivistic quantitative research terms for inter-subjective qualitative research in other cultures.

\section{REFERENCES}

[1] Benton, Ted and Ian Craib. "Philosophy of Social Science." New York: Palgrave (2001).

[2] Hardiman, F. Budi. Pustaka Filsafat Melampaui Positivisme dan Modernitas [Philosophy Beyond Positivism and Modernity]. Kanisius, 2003.

[3] Hardiman, F. Budi. "Seni Memahami" [The Art of Understand] Yogyakarta: Kanisius (2015).

[4] Lett, James William. "The human enterprise: A critical introduction to anthropological theory." (1987).

[5] Moleong, Lexy J., and Tjun Surjaman. Metodologi penelitian kualitatif [Qualitative Research Methodology]. Penerbit PT Remaja Rosdakarya, 1991.

[6] Poespowardojo, T. M. "Soerjanto, dan Alexander Seran." Filsafat Ilmu Pengetahuan: Hakikat Ilmu Pengetahuan Kritik terhadap Visi Positivisme Logis, serta Implikasinya [Philosophy of Science: The Notion of Science Criticism towards the Vision of Logical Positivism, and its Implications].” Jakarta: Kompas (2015).

[7] Pradoko, A.M.Susilo. "Perubahan Pemaknaan Candi Siwa Prambanan Sejak Abad ke-9 Hingga Abad ke-20: Kajian Arkeologi Pengethuan [Changes in the Meaning of Shiva Prambanan Temples From the 9th Century to the 20th Century: Study of Archaeological Studies]." Depok: Disertasi, Program Studi Arkeologi FIB UI, 2015.

[8] Pradoko, A.M.Susilo. "Paradigma Metode Penelitian Kualitatif Keilmuan Seni ,Humaniora dan Budaya [The Paradigm of Qualitative Research Methods in the Scientific Art, Humanities and Culture].’YYogyakarta: UNY Press (2017) 